\title{
An Entropy Weight Method of Collaborative Degree Model Between Producer Service Industry and Manufacturing Industry
}

\author{
Deguang Liu \\ Business School of Hohai University, Nanjing, 211100, China \\ Received: January 16, 2021. Revised: July 7, 2021. Accepted: July 18, 2021. Published: July 20, 2021.
}

\begin{abstract}
In order to study the coupling coordination relationship, the equipment manufacturing industry has been taken as the example to develop the evaluation index system of producer services and equipment manufacturing industry through employing the entropy weighting method. The relationship between them has been verified in the whole country. The research results show that there is a symbiotic relationship between the producer services and the equipment manufacturing industry. Both of them are mutually promoted and symbiotically developed. The unbalanced economic development in all regions of China is dominated by the synergy degree difference of both sides, which provides the guidance for the regional economic development in our country.
\end{abstract}

Keywords-logistic model, Entropy weighting method, synergy degree measurement, Index system, symbiotic development

\section{INTRODUCTION}

A $\mathrm{S}$ a service industry, the producer services belong to the third industry that mainly provides the service for the producers of goods and service[1]. At present, China is during the economic transition period and the producer services can provide service for all industries. The investment share in the second industry is more than $50 \%$ and the manufacturing industry is an important part of the second industry, which means that there is a close relationship between them[2-4].

The aim is to explore the symbiotic relationship and the matching strategies so as to provide the guidance for the economic macro-control in our country. Lin Muxi et al (2013) has pointed out that the "pulling force" for producer services is insufficient; meanwhile, the producer services is "small and scattered" and the "propulsive force" for equipment manufacturing industry is not enough[5-6]. Chu Mingqin (2013) has pointed out that the producer services is still low at present, in which the proportion of producer services has been declined and the proportion of equipment manufacturing industry has been increased; however, the rate of increase value has been greatly decreased[7-9].
In this paper, based on the uneven matching of producer services and equipment manufacturing industry, the entropy weighting method is proposed to process the evaluation index of the development and analyze the symbiotic development coordination relationship of them from the perspective of empirical research so as to provide support for China's macroeconomic regulation and control.

\section{SYMBIOTIC DEVELOPMENT MODEL OF PRODUCER SERVICES AND MANUFACTURING INDUSTRY}

A. Population Growth Equation of Producer Services and Manufacturing Industry

The population quantity of producer services (PS) and the population quantity of manufacturing industry (MI) are obviously dominated by the environmental factors such as resources, technology and system. Therefore, the evolution of the population quantity is in density dependence and it can be described by Logistic model.

Assuming that: the population density of producer services is $N_{1}$, the natural growth rate is $r_{1}$ and the environmental capacity of population is $K_{1}$; the population density of manufacturing industry is $N_{2}$, the natural growth rate is $r_{2}$ and the environmental capacity of population is $K_{2}$. The growth equation of both sides' populations is shown in formula (1)

$$
\begin{aligned}
& \frac{d N_{1}}{d t}=r_{1} N_{1}\left(1-\frac{N_{1}}{K_{1}}\right) \\
& \frac{d N_{2}}{d t}=r_{2} N_{2}\left(1-\frac{N_{2}}{K_{2}}\right)
\end{aligned}
$$

The population growth equation of both sides contains the following four hypotheses:

Hypothesis 1. the population growth of both sides is constrained by the resources and the market demands. When the population density is increased to a certain degree and enters the decreased stage, there will exist the maximum population densities $K_{1}$ and $K_{2}$. 
Hypothesis 2. the natural growth rates $r_{1}, r_{2}$ of both sides in ideal conditions are determined by the inherent properties of the two populations;

Hypothesis 3. the population attributes of both sides are not changed in the observation period; the evolution of population is ignored and the natural growth rate $r_{1}, r_{2}$ are unchanged.

Hypothesis 4. with the increase of the population density of both sides, the resources are strained and the population competition is intensified, which produces the inhibition effects $\left(1-\frac{N_{1}}{K_{1}}\right)$ and $\left(1-\frac{N_{2}}{K_{2}}\right)$ for the population increase rates of both sides.

\section{B. Symbiotic Development Model of Producer Services and Manufacturing Industry}

The symbiotic development model of both sides can be represented as

$$
\begin{array}{r}
\frac{d N_{1}}{d t}=r_{1} N_{1}\left(1-\frac{N_{1}}{K_{1}^{0}+K_{12} f_{12}\left(N_{2}\right)}\right) \\
\frac{d N_{2}}{d t}=r_{2} N_{2}\left(1-\frac{N_{2}}{K_{2}^{0}+K_{21} f_{21}\left(N_{1}\right)}\right)
\end{array}
$$

In the above formula, $K_{1}^{0}$ and $K_{2}^{0}$ are the environmental capacities to remove the symbiotic effect; $K_{12}, K_{21}$ are respectively the symbiotic interaction coefficients of manufacturing industry population for producer services population and the producer services population for the manufacturing industry population.

If it is assumed that the environmental capacity is $\Delta E$ and the interaction coefficients of environmental changes for the population environmental capacity of producer services and manufacturing industry are respectively $\beta_{1}, \beta_{2}$, the symbiotic development model of producer services and manufacturing industry populations under the influence of environment should be corrected as

$$
\begin{aligned}
& \frac{d N_{1}}{d t}=r_{1} N_{1}\left(1-\frac{N_{1}}{K_{1}^{0}+K_{12} f_{12}\left(N_{2}\right)+\beta_{1} f_{1}(\Delta E)}\right) \\
& \frac{d N_{2}}{d t}=r_{2} N_{2}\left(1-\frac{N_{2}}{K_{2}^{0}+K_{21} f_{21}\left(N_{1}\right)+\beta_{2} f_{2}(\Delta E)}\right)
\end{aligned}
$$

According to formula (5) and formula (6), the environmental capacities of the symbiotic populations of producer services and manufacturing industry under the influence of environmental changes can be respectively expressed as

$$
\begin{array}{r}
K_{1}=K_{1}^{0}+K_{12} f_{12}\left[N_{2}(t)\right]+\beta_{1} f_{1}[\Delta E(t)]=f_{1}^{S E}(t) \\
K_{2}=K_{2}^{0}+K_{21} f_{21}\left[N_{1}(t)\right]+\beta_{2} f_{2}[\Delta E(t)]=f_{2}^{S E}(t)
\end{array}
$$

In formula (7) and formula (8), it can be found that the environmental capacities $K_{1}$ and $K_{2}$ of the symbiotic populations of both sides are considered to be a complex curve. In addition, the observation time is broken down into many smaller time periods, the environmental capacity of both sides' populations is called the following fixed value in any period of time $\left[t_{T}, t_{T+1}\right](T=0,1,2, \cdots)$

$K_{1}^{T+1}=K_{1}^{0}+K_{12} \frac{f_{12}\left[N_{2}\left(t_{T}\right)\right]+f_{12}\left[N_{2}\left(t_{T+1}\right)\right]}{2}+\beta_{1} \frac{f_{1}\left[\Delta E\left(t_{T}\right)\right]+f_{1}\left[\Delta E\left(t_{T+1}\right)\right]}{2}$

$K_{2}^{T+1}=K_{2}^{0}+K_{21} \frac{f_{21}\left[N_{1}\left(t_{T}\right)\right]+f_{12}\left[N_{1}\left(t_{T+1}\right)\right]}{2}+\beta_{2} \frac{f_{1}\left[\Delta E\left(t_{T}\right)\right]+f_{1}\left[\Delta E\left(t_{T+1}\right)\right]}{2}(10)$

Giving that $\Delta t \in\left[0, t_{T+1}-t_{T}\right]$, the density growth of symbiotic populations in the period of time $\left[t_{T}, t_{T+1}\right]$ is consistent with the Logistic equation

$$
\begin{aligned}
& \frac{d N_{1}}{d \Delta t}=r_{1} N_{1}\left(1-\frac{N_{1}}{K_{1}^{T+1}}\right) \\
& \frac{d N_{2}}{d \Delta t}=r_{2} N_{2}\left(1-\frac{N_{2}}{K_{2}^{T+1}}\right)
\end{aligned}
$$

The dynamic curve of population symbiotic development under the influence of environmental changes are shown in Figure 1. It can be seen from this Figure The species curve of producer services (PS) and manufacturing industry (MI) populations often appears bifurcation

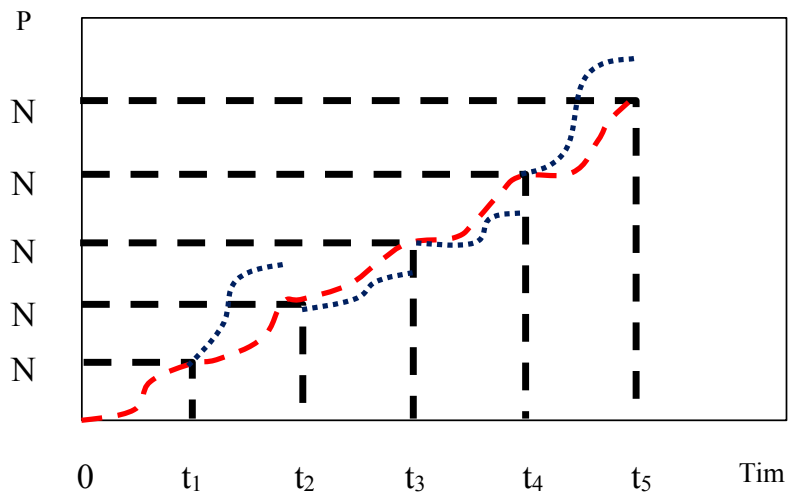

Fig. 1 Dynamic curve of population symbiotic development under the influence of environmental changes

\section{SYNERGY DEGREE MEASUREMENT MODEL BASED ON ENTROPY WEIGHTING METHOD}

\section{A. Entropy Weighting Method}

The basis of the synergy degree research of both sides is the change process of system related factors and the main selection of system order parameters can reflect the index of economic development changes. Assuming that the order parameter in the system development process is $x_{i j}, i \in[1, n], j \in[1, m], n \geq 1, m \geq 1$, and $\lambda_{i j}, \mu_{i j}$ are the limited values of each order parameter, i.e. $\mu_{i j}<x_{i j}<\lambda_{i j}$.

The order degree of order parameter components of economic system can be defined as 


$$
y_{i j}\left(x_{i j}\right)=\left\{\begin{array}{lc}
\frac{x_{i j}-\mu_{i j}}{\lambda_{i j}-\mu_{i j}} & ,(j=1,2, \cdots, k) \\
\frac{\lambda_{i j}-x_{i j}}{\lambda_{i j}-\mu_{i j}} & ,(j=k+1, k+2, \cdots, m)
\end{array}\right.
$$

$y_{i j}\left(x_{i j}\right) \in(0,1), y_{i j}\left(x_{i j}\right)$ is close to 0 , so the lower the degree of order parameter component is, the smaller the contribution for system will be. On the contrary, the contribution for system will be larger.

The overall order degree of the corresponding system of the order parameter $x_{i j}$ in each system can be realized by the integration of $y_{i j}\left(x_{i j}\right)$ and the formula is as follows

$$
z\left(x_{i}\right)=\sum_{j=1}^{m} \omega_{j i} y_{i j}\left(x_{i j}\right),\left(\omega_{j i} \geq 0, \sum_{j=1}^{m} \omega_{j i}=1\right)
$$

In formula (14), $\omega_{j i}$ is the weight of each order parameter and $z\left(x_{i}\right)$ is the overall order degree of order parameter for each system. $z\left(x_{i}\right) \in(0,1)$, the greater $z\left(x_{i}\right)$ is, the higher the order degree of system will be. On the contrary, the order degree will be lower.

Considering that the index data difference of model is relatively large, the entropy weighting method is employed [10] to determine the index. Each index is quantified in the same degree,

$$
p_{i j}=\frac{y_{i j}\left(x_{i j}\right)}{\sum_{i=1}^{n} y_{i j}\left(x_{i j}\right)}
$$

Calculating the entropy of the components of order parameter,

$$
e_{j}=\frac{1}{\ln n} \sum_{i=1}^{n} p_{i j} \ln p_{i j}
$$

In the above formula, $e_{j}$ represents the entropy of the $j$ th evaluation index, $e_{j}>0, \ln n>0$. The difference coefficient can be obtained by the formula (17)

$$
g_{j}=1-e_{j}
$$

In order to make $\ln p_{i j}$ meaningful, the difference coefficient $g_{j}$ is introduced and $\omega_{i j}$ is corrected. The greater $g_{j}$ is, the more concerned the index will be. The normalized difference coefficient is

$$
\omega_{j}=\frac{g_{j}}{\sum_{j=1}^{m} g_{j}}
$$

The weight coefficient matrix is obtained: $R_{\omega}=\left\{\omega_{1}, \omega_{2}, \cdots, \omega_{n}\right\}$.

\section{B. Synergy Degree Measurement Model}

The coordination coefficient is the index that reflects the quantity degree of the combination and the coordination of economic benefits. Assuming that the comprehensive evaluation functions of the economic system of producer services and equipment manufacturing industry at the time point $t$ are respectively $f(r, t)$ and $f(c, t)$, then

$$
f(r, o r, c)=\sum_{j=1}^{m} \omega_{j} y_{i j}\left(x_{i j}\right)
$$

The capacity coupling coefficient model in physics has been employed to calculate the coordination coefficient[13] and it is required to define that

$$
C I=2 \sqrt{\frac{f_{(r, t)} \times f_{(c, t)}}{\left(f_{(r, t)}+f_{(c, t)}\right)^{2}}}
$$

In which $C I \in[0,1]$, the value of $C I$ is closer to 1 , the both sides will be coordinatedly developed. On the contrary, the development will be not coordinated.

As the important index to describe the mutual coordination of both sides at time $\boldsymbol{t}$, the coordination coefficient is of great significance for restricting the system development and promoting the coordinated development of system. However, two systems have the dynamic and unbalanced characteristics and the coordination coefficient can not show the overall function or the comprehensive economic benefits of the two systems. Therefore, the synergy degree is introduced as the index to measure the synergy development degree of the two systems.

$$
\begin{gathered}
D(t)=\sqrt{C I \times T} \\
T=\alpha \cdot f_{(r, t)}+\beta \cdot f_{(c, t)}
\end{gathered}
$$

In the above formulas, $D(t)$ represents the synergy degree, $C I$ refers to the coordination coefficient, $T$ represents the comprehensive evaluation function of overall benefits or levels and $\alpha, \beta$ refer to the weights.

Assuming that the both sides are of the same importance, that is $\alpha, \beta$ take $0.5, C I$ and $T$ are taken into the formula $D(t)$ to obtain

$$
D(t)=\sqrt[4]{f_{(r, t)} \times f_{(c, t)}}
$$

In the above formula, $0 \leq D(t) \leq 1$, when $D(t) \rightarrow 1$, the synergy degree will be larger. If the synergy development between both sides or among the internal elements is realized, the system will tend to a new order structure; on the contrary, the synergy degree is smaller, extraneous state will exist in the two systems or internal elements and the system will be disorderly 
developed.

\section{EMPIRICAL ANALYSIS}

\section{A. Construction of Evaluation Index System}

In this paper, from the perspectives of scale index, structure index, growth index and efficiency index, the evaluation index system for both sides has been built. The first-order index of equipment manufacturing industry contains the scale $\mathrm{X} 1$, the structure $\mathrm{X} 2$, the growth $\mathrm{X} 3$ and the efficiency $\mathrm{X} 4$; the firstorder index of producer services includes the scale $\mathrm{Y} 1$, the structure Y2, the growth Y3 and the efficiency Y4.

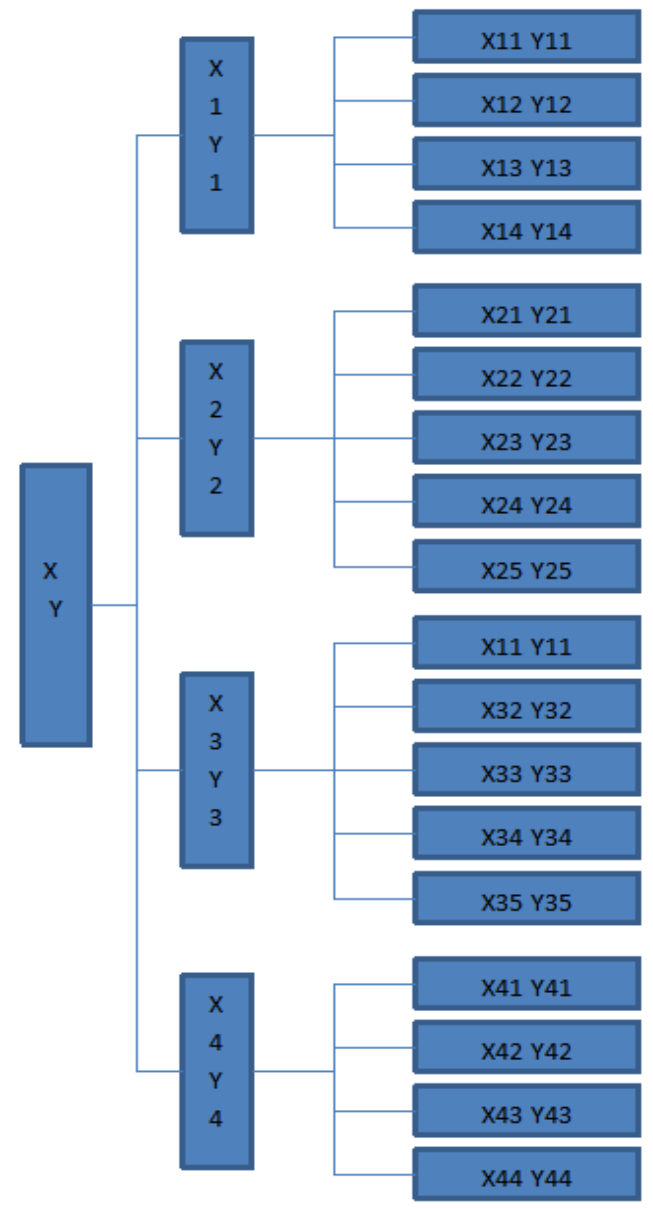

Fig.2 Hierarchy framework of evaluation index system

The second-level index of X1 includes the total output value of equipment manufacturing industry $\mathrm{X} 11$, the number of equipment manufacturing enterprises X12, the average number of equipment manufacturing industry employment X13 and the total amount of profit taxation in equipment manufacturing industry X14; the second-level index of X2 contains the total industrial output value $\mathrm{X} 21$, the proportion of the total industrial output value of equipment manufacturing industry in the total industrial output value $\mathrm{X} 22$, the proportion of equipment manufacturing employment in the industrial employment X23, the proportion of equipment manufacturing enterprises in the industrial enterprises X24 and the proportion of the profit taxation of equipment manufacturing industry in the industrial profit taxation X25; the second-level index of X3 includes the growth rate of the total industrial output value of equipment manufacturing industry $\mathrm{X} 31$, the increase rate of equipment manufacturing enterprises $\mathrm{X} 32$, the increase rate of equipment manufacturing employment X33, the increase rate of the profit taxation of equipment manufacturing industry X34 and the growth rate of the fixed asset of equipment manufacturing industry X35; the second-levle index of X4 contains the employment contribution rate of equipment manufacturing industry $\mathrm{X} 41$, the profit taxation of the equipment manufacturing production value $\mathrm{X} 42$, the increase rate of the equipment manufacturing asset hedge X43 and the coverage rate of the equipment manufacturing assets $\mathrm{X} 44$; the second-level index of $\mathrm{Y} 1$ includes the increase value of producer services $\mathrm{Y} 11$, the number of producer services enterprises Y12, the average number of producer services employment Y13 and the total amount of producer services taxes Y14; the second-level index of Y2 contains the proportion of the third industrial added value in GDP Y21, the proportion of producer services added value in the third industrial added value Y22, the proportion of producer services employment in the third industrial employment Y23, the proportion of producer services enterprises in the third industrial enterprises Y24 and the proportion of the total taxes of producer services in the total taxes of the third industry Y25; the second-level index of Y3 includes the growth rate of producer services added value Y31, the increase rate of producer services enterprises Y32, the growth rate of producer services employment Y33, the increase rate of producer services taxes $\mathrm{Y} 34$ and the growth rate of the fixed assets of producer services Y35; the second-level index of Y4 contains the employment contribution rate of producer services Y41, the labor productivity of producer services 42 , the proportion of producer services taxes in added value Y43 and the investment effect coefficient of the fixed assets of producer services Y44. The hierarchy framework of evaluation index system is shown in Figure 2.

\section{B. Empirical Results and Analysis of the Symbiotic} Coordination Degree

According to the method of literature review, it is given that $\alpha=0.4, \beta=0.6$ in formula (21) and $T=0.4 \cdot f_{(r, t)}+0.6 \cdot f_{(c, t)}$. The calculation results of the coordination degree of producer services and equipment manufacturing industry based on entropy weighting method in major areas of our country are shown as follow

Tab. 1 Optimal solution and mean convergence table

\begin{tabular}{cccccc}
\hline Region & $\mathrm{f}(\mathrm{r}, \mathrm{t})$ & $\mathrm{f}(\mathrm{c}, \mathrm{t})$ & $\mathrm{D}(\mathrm{t})$ & $\begin{array}{c}\text { Coordination } \\
\text { levels }\end{array}$ & $\begin{array}{c}\text { Symbiotic } \\
\text { levels }\end{array}$ \\
\hline Jiangsu & 0.7078 & 0.5427 & 0.7759 & & \\
Shanghai & 0.5053 & 0.5945 & 0.7445 & & \\
Beijing & 0.3788 & 0.6514 & 0.7284 & & \\
Zhejiang & 0.5479 & 0.4968 & 0.7205 & & \\
Shandong & 0.5129 & 0.4969 & 0.7082 & & \\
Fujian & 0.3323 & 0.4071 & 0.6185 & primary & primary \\
Liaoning & 0.4132 & 0.3555 & 0.6134 & coordination & symbiosis \\
Hubei & 0.3813 & 0.3512 & 0.6007 & & \\
Hebei & 0.3369 & 0.3720 & 0.5957 & & \\
\hline
\end{tabular}




\begin{tabular}{cccccc}
\hline Henan & 0.3850 & 0.3313 & 0.5919 & & \\
Chongqing & 0.3658 & 0.3119 & 0.5746 & & \\
Anhui & 0.3869 & 0.2916 & 0.5708 & & \\
Sichuan & 0.3370 & 0.3263 & 0.5704 & & \\
Neimenggu & 0.2491 & 0.3914 & 0.5678 & & \\
Guangxi & 0.3668 & 0.3011 & 0.5669 & & \\
Jilin & 0.3611 & 0.2919 & 0.5623 & & \\
Hunan & 0.3413 & 0.2885 & 0.5521 & & \\
Tianjin & 0.3251 & 0.3705 & 0.5512 & barely & \\
Shaanxi & 0.2946 & 0.2874 & 0.5371 & coordination & \\
shanxi & 0.2372 & 0.3426 & 0.5362 & & \\
Jiangxi & 0.3179 & 0.2630 & 0.5298 & & \\
Heilongian & 0.2441 & 0.2840 & 0.5148 & & \\
g & & & & \\
Yunnan & 0.2279 & 0.2860 & 0.5097 & & \\
Guizhou & 0.2371 & 0.2804 & 0.5086 & & \\
Ningxia & 0.2540 & 0.2624 & 0.5067 & & no \\
Xinjiang & 0.2685 & 0.2482 & 0.5039 & & primary \\
Hainan & 0.2139 & 0.2902 & 0.5031 & & symbiosis \\
Gansu & 0.2484 & 0.2125 & 0.4744 & on the verge \\
Qinghai & 0.2270 & 0.1929 & 0.4507 & of disorder \\
Xizang & 0.1211 & 0.1853 & 0.3824 & & symbiosis \\
nationwide & 0.3735 & 0.3840 & 0.6154 & coordination & \\
& & & & & \\
\hline
\end{tabular}

The data in above table is the average value of the measurement results of coordination degree in 2016-2020. Based on the data, it is found that there exist obvious differences in the symbiosis levels of producer services and equipment manufacturing industry in all provinces and municipalities and the development is not balanced. The symbiosis level has shown a gradient decrease from east to west. The average value of the coupling coordination degree in eastern regions is 0.70 and it is at the intermediate level of symbiosis. The average value in some provinces and municipalities in east regions is more than 0.6 and it is in the evolution stage from primary symbiosis to intermediate symbiosis; the average value of coupling coordination degree in central regions is 0.60 and it is at the primary level of symbiosis; the average value of coupling coordination degree in western regions is only 0.50 and it is also at the primary level of symbiosis. However, there also exists no symbiosis between two industries in some regions. This trend is consistent with China's regional economic development and industrialization process. The higher the coupling coordination degree is, the higher the symbiosis level of the two industries will be. The economic development in central and western regions lags behind the one in eastern regions and the development of the two industries also falls behind the one in eastern regions, so the symbiosis level is lower; the main reason lies that the symbiosis levels are closely linked with the development of producer services and equipment manufacturing industry.

\section{CONCLUSION}

There exists the symbiotic relationship between the producer services and the equipment manufacturing industry. The optimal coupling of them can be realized by the coordination development, consistent steps and seamless matching. In this paper, the synergy relationship has been studied from the empirical perspective. The research results show that the necessary condition of the benign development of producer services and equipment manufacturing industry refers to the coupling coordination of them and the regional economic characteristics are consistent with the research results.

In the future, we can consider using the calculation method of grey absolute correlation degree to give the absolute correlation degree. By calculating the similarity of the slope of the curve of the two columns of time data in the corresponding time periods and points, the proximity of the two curves can be determined. If the slope of the two curves in the corresponding time periods or time points is equal or the difference is small, the greater the correlation between the two curves, and vice versa. Of course, there is no grey correlation degree algorithm that can meet the requirements of order preservation and normalization at the same time. Therefore, in practical application, we can adjust or relax the definition of normative, because order preservation is more important for practical application.

\section{REFERENCES}

[1] Xia Hu,Producer services agglomeration and urban economic growth in China: an analysis based on threshold regression,Journal of Guangdong Administration College,2016,28(2),pp.1-9.

[2] Liangqun Cen, Yuanyuan Cai, Chengdong Wang. Industrial R\&D Input Stucture Oriented by the R\&D Efficiency,China Science and Technology Forum, 2015(4),pp.11-16.

[3] Chengdong Wang.Study on the Driving Intensity of Industrial Convergence Driving Factors of Equipment Manufacturing Industry and Producer Service Industry,Scientific and Technological Progress and Countermeasures, 2015,32(3),PP.60-64.

[4] Jiang Wang, Lei Tao,The Study on the Influence of China's Equipment Manufacturing Industy 'Going out' on the Development of Productive Service Industry:An Empirical Analysis Based on VAR Model,Journal of University of International Business and Economics, 2016(4),pp.37-45.

[5] Junyue Liu, Kan Wan, Sheng Zhong,Coupling Coordination between Producer Service Industry and Equipment Manufacturing Industry in Chongqing,Journal of Wuhan University of Technology, 2012, 34(4),pp.485-489.

[6] Muxi Lin, Chun Cui. The Regional Comparison of Interactive Development between the Equipment Manufacturing Industy and Producer services in China,Industrial Technology \& Economy, 2013(6),pp.3-9.

[7] Mingqin Chu. Study on Industrial Relevancy between Machinery Industry and Producer Services:Based on the Comparative Analysis of China Input-output Table,Economic Issues in China, 2013(5),pp.79-88.

[8] Sukanya Intarapak, Thidaporn Supapakorn, Application of Logistic Regression Analysis to Household Debt of Bangkok and Metropolitan Area of Thailand, WSEAS Transactions on Business and Economics, Volume 17, 2020, Art. \#65, pp. 676-681.

[9] Saleh Ali Alomari, Safwan Al Salaimeh, Emran Al Jarrah, Mowafaq Salem Alzboon, Enhanced Logistics Information Service Systems Performance: Using Theoretical Model and Cybernetics?Principles, WSEAS Transactions on Business and Economics, Volume 17, 2020, Art. \#29, pp. 278-287.

[10] Jiskani I M , Han S, Rehman A U, et al. An Integrated Entropy Weight and Grey Clustering Method-Based Evaluation to Improve Safety in Mines. Mining Metallurgy \& Exploration, 2021(10),pp.237-249.

\section{Creative Commons Attribution License 4.0 (Attribution 4.0 International, CC BY 4.0)}

This article is published under the terms of the Creative Commons Attribution License 4.0

https://creativecommons.org/licenses/by/4.0/deed.en_US 